\title{
BUENA OPORTUNIDAD PARA APROBAR AHORA UNA RENTA BÁSICA INCONDICIONAL EN LA COMUNIDAD AUTÓNOMA VASCA
}

\author{
Good opportunity to approve now an unconditional Basic Income \\ in the Basque Autonomous Community
}

\author{
Ángel Elías Ortega*
}

Profesor Titular, Universidad del País Vasco/Euskal Herriko Unibertsitatea (España)

\section{RESUMEN}

Después de una breve introducción, describo el modelo de rentas mínimas y garantizadas vigente en Euskadi para, a continuación, explicar el contenido principal de esta Iniciativa Legislativa Popular, incluyendo una mención a su financiación, tras lo que enumero el respaldo que la Renta Básica Incondicional tiene en los últimos ańos, para examinar después los beneficios que derivan de algunas de sus potencialidades como son las de poner fin a la pobreza, generar salud y bienestar, afrontar la creciente desigualdad y avanzar en otros grandes retos como son el cumplimiento de los Objetivos de Desarrollo Sostenible.

Palabras clave: renta básica, reparto, pobreza, desigualdad, salud.

\section{ABSTRACT}

After a brief introduction, I describe the model of minimum and guaranteed incomes in force in the Basque Country and then explain the main content of this Popular Legislative Initiative, including a mention of its financing, after which I list the support that the Unconditional Basic Income has received in recent years, to then examine the benefits derived from some of its potential to end poverty, generate health and well-being, tackle growing inequality and make progress in other major challenges such as the fulfilment of the Sustainable Development Goals.

Keywords: basic income, distribution, poverty, inequality, health.

\section{LABURPENA}

Sarrera labur baten ondoren, Euskadin indarrean dagoen gutxieneko eta bermatutako errenten eredua deskribatzen dut eta, segidan, Herri Ekimen Legegile honen eduki nagusia deskribatzen dut, haren finantzaketaren aipamen bat barne, eta horren ondoren, Oinarrizko Errenta Baldintzagabeak azken urteetan duen babesa zerrendatzen dut, ondoren haren potentzialitate batzuen ondoriozko onurak aztertzeko, hala nola pobrezia amaitzeko, osasuna eta ongizatea sortzeko, gero eta handiagoa den desberdintasunari aurre egiteko eta beste erronka handi batzuetan aurrera egiteko, hala nola Garapen Jasangarriko Helburuak betetzean.

Gako-hitzak: oinarrizko errenta, banaketa, pobrezia, desberdintasuna, osasuna.

* Correspondencia a: Ángel Elías Ortega. Santsoena Auzoa, 26, Leioa (Bizkaia), España. — angel.elias@ehu.eus — https: //orcid. org/0000-0002-7927-8835

Cómo citar: Elías Ortega, Ángel. (2021). «Buena oportunidad para aprobar ahora una Renta Básica Incondicional en la Comunidad Autónoma Vasca»; Lan Harremanak, 46, 84-113. (https: //doi.org/10.1387/lan-harremanak.23177).

Recibido: 11 noviembre, 2021; aceptado: 20 diciembre, 2021.

ISSN 1575-7048 - elSSN 2444-5819 / (c) 2021 UPV/EHU

(c) (i) Esta obra está bajo una licencia

Creative Commons Atribución 4.0 Internaciona 


\section{Introducción}

El 18 de febrero de 2021 se entregó en la Secretaría General de la Mesa del Parlamento Vasco una solicitud de tramitación de una Iniciativa Legislativa Popular, en lo sucesivo ILP ${ }^{1}$, para una Renta Básica Incondicional, en lo sucesivo RBI, en la Comunidad Autónoma del País Vasco, en lo sucesivo CAPV, firmada por dos personas, en nombre de una Promotora de 16 miembros, todas ellas ligadas con distintos sectores de la sociedad vasca ${ }^{2}$. Con fecha de 16 de marzo de 2021 la Mesa del Parlamento acuerda otorgar el anticipo de 2.000 euros para cubrir los primeros gastos de la recogida de firmas y, a su vez, la Junta Electoral Central de la CAPV, en sesión celebrada el 6 de septiembre de 2021, acuerda que el plazo de cuatro meses para la recogida de firmas comenzará el día siguiente a la notificación del presente acuerdo a la Comisión Promotora de la ILP, lo que sucedió ese mismo día.

Según la Comisión Promotora (2021) el objetivo de esta ILP es transformar el sistema. Afirma que:

Nos encontramos con una convicción clara y un objetivo común: la urgencia de acabar con la pobreza, repartir la riqueza y avanzar en una sociedad que proteja el derecho a una renta que garantice unas condiciones mínimas materiales para una vida digna. Aunque la solución a estos problemas requiere intervenciones complejas en distintos ámbitos interconectados, estamos convencidas de que una Renta Básica Incondicional es capaz de proporcionar de forma inmediata mayores garantías para los derechos fundamentales, y que puede desbloquear los obstáculos para avanzar en distintas reivindicaciones y caminos para transformar un sistema que se ha revelado injusto para la mayoría, que erosiona el planeta y reproduce sistemas de dominación que deben ser erradicados.

Esta ILP llega en un momento donde los grandes retos locales y globales son los de hacer frente a la pandemia del Covid19; a la muy agravada crisis climática, que ha derivado en la declaración del estado de emergencia climática; y a una creciente desigualdad que mantiene en la miseria a millones de personas en el mundo, también en los llamados países desarrollados, y otorga el poder a unas minorías multimillonarias, lo que requiere de nuevos enfoques en las políticas económicas, y también en la cultura, donde es inaplazable conseguir la igualdad de mujeres y hombres, y hacer frente a un nuevo escenario donde la inteligencia

1 La Ley 10/2016, de 30 de junio, del Parlamento Vasco, reguladora de la Iniciativa Legislativa Popular, sustituye a la anterior Ley 8/1986, de 26 de junio, y pretende facilitar que la ciudadanía y los grupos sociales tomen parte en la función legislativa, haciendo más sencillo y menos restrictivo que puedan proponer iniciativas que luego sean debatidas en el Parlamento.

2 Son personas residentes en Bizkaia, Gipuzkoa y Araba, de distintas generaciones y con recorridos diversos en el campo de los derechos humanos, la lucha contra la pobreza y la exclusión, el antirracismo, el feminismo, el ecologismo o el antimilitarismo (entre otras). 
artificial esté al servicio del conjunto de la humanidad, lo que exige nuevos enfoques al reparto de la riqueza y del trabajo.

Una muestra del discurso oficial ante estos retos en la CAPV aparece en el Prólogo del IV Plan Director de Cooperación para el Desarrollo (Gobierno Vasco: 2018), firmado por el lehendakari Ińigo Urkullu, que contiene las reflexiones siguientes:

El marco global y el local se encuentran más interrelacionados y se está consolidando una nueva agenda de preocupaciones adaptadas a la realidad del siglo xxi. Se trata de debates emergentes relacionados con la gestión de valores como la diversidad y la solidaridad en la convivencia o la educación, así como con cuestiones que afectan directamente a la consideración de los derechos humanos.

Estas realidades emergentes no se asientan todavía en el suelo firme de un discurso sólido; abren reflexiones y debates de posiciones que cuestionan principios que hasta este momento se consideraban incuestionables y que afectan a valores, derechos y libertades fundamentales. En este sentido, es muy posible que la defensa de los derechos humanos y, en consecuencia, el deber de solidaridad, representen la gran tarea de las primeras décadas de este siglo xxI.

Hoy participamos de un pulso social, político e ideológico entre dos valores de referencia: individualismo o solidaridad. Mirando al futuro, nos estamos jugando si en las próximas décadas el centro de gravedad tiende a reforzar el valor de la solidaridad o, por el contrario, profundiza en el valor del individualismo. La evolución es relevante porque su proyección va a tener incidencia en la conciencia de la ciudadanía, así como en los diferentes ámbitos de la política local y global.

Esta reflexión se sitúa en la base de dicho proceso y adquiere un alcance estratégico a la hora de enfocar las actuaciones de estos próximos cuatro años. En este sentido, compartir social e institucionalmente la importancia de los derechos humanos, la implicación en la solidaridad y la fuerza del sentido y utilidad de la cooperación es fundamental.

Compartimos, por un principio ético, que es imperativo promover y construir un mundo en el que las condiciones básicas de igualdad, justicia, paz y libertad alcancen especialmente a las personas más vulnerables. Además, asumimos, por un objetivo pragmático, que la extensión local y global de un desarrollo humano y sostenible es la mejor estrategia para propiciar contextos de bienestar y seguridad presente y futura. Aspiramos a vivir en un mundo que sea capaz de compartir los bienes básicos de la alimentación, la vivienda, la educación, la sanidad, la autonomía, la libertad y la paz.

(...)

La política de cooperación del Gobierno Vasco se alineará además con los Objetivos de Desarrollo Sostenible y las metas que marca la Agenda 2030 de Naciones Unidas. En este marco de referencia compartimos la visión de un mundo centrado en las Personas, comprometido con la protección del Planeta y la convivencia en Paz, y capaz de generar Prosperidad a través de un modelo de alianzas o Partenariado.

Personas, Planeta, Paz, Prosperidad y Partenariado son las cinco esferas de importancia crítica para la humanidad y el planeta, asumidas con la promesa de «no dejar a nadie atrás», un compromiso que conecta directamente con el espíritu vasco de solidaridad que nos ha caracterizado a lo largo del tiempo. La sociedad vasca ha sido 
y es solidaria. Esta solidaridad es la base del itinerario que hemos seguido, trabajando siempre en colaboración con la sociedad civil organizada y, especialmente, con las Organizaciones No Gubernamentales de Desarrollo vascas que han sido una pieza básica en la construcción de un modelo de cooperación propio reconocible, reconocido y apreciado.

(...)

El enfoque de Derechos Humanos, el Desarrollo Humano Sostenible, la Agenda 2030, la Coherencia de Políticas para el Desarrollo y Auzolana son los parámetros que definen nuestra estrategia.

Sin embargo, la Encuesta de Pobreza y Desigualdades Sociales, en adelante EPDS, que publica bienalmente el Gobierno Vasco (2021) ${ }^{3}$ revela que 132.173 personas se encontraban en el año 2020 en situación de pobreza severa en el País Vasco. Por ello, a continuación, describiré el modelo de rentas mínimas y garantizadas vigente en esta Comunidad Autónoma, para luego explicar el contenido principal de esta ILP, así como los motivos por lo que considero que su aprobación en la CAPV es una buena oportunidad para avanzar en los grandes retos actuales.

\section{El modelo de rentas mínimas garantizadas y condicionadas implantado en el País Vasco}

El 16 de septiembre de 1988, en Estrasburgo, el Parlamento Europeo adoptó una resolución de lucha contra la pobreza, por la que instaba a los poderes públicos a la instauración de una renta mínima garantizada para favorecer la inserción de los ciudadanos más pobres en la sociedad. El 1 de diciembre de 1988 se aprueba en Francia la ley relative au revenu minimum d'insertion, que materializa el ingreo minimo de inserción, en lo sucesivo IMI, como un sistema de garantía de ingresos que busca blindar el «derecho a obtener un medio de existencia adecuado" para "cualquier persona que, debido a su edad, su estado físico o mental, el estado de la economía y el empleo" no pueda trabajar de forma remunerada (Loi n. ${ }^{\circ} 88-1088$ ).

El IMI se presenta como alternativa a los sistemas de asistencia social basados exclusivamente en una prestación económica de las décadas de la posguerra. En este nuevo escenario de altas tasas de desempleo, el IMI establece los dos pilares que impregnarán los sistemas de garantía de ingresos que pronto se propagarán por los otros estados del sur de Europa —España, Portugal o Italia-: la dimensión monetaria y la dimensión de la inclusión laboral. Lo mismo ocurrió en años posteriores en gran parte de los estados europeos - Suecia, Holanda,

${ }^{3}$ La última EPDS, que incluye el año 2020, ha sido publicada en mayo de 2021. 
Noruega, Dinamarca, Alemania, Finlandia o Reino Unido-, donde las políticas de activación obligatorias también fueron fortalecidas (Aust y Arriba, 2005), ligando la garantía de ingresos a acciones de inclusión laboral y entendiendo dichos procesos como parte esencial hacia la restauración del vínculo social de las personas beneficiarias. De este modo, como escribió Clasen (2001), la asistencia social atraviesa la barrera de ser un derecho social para convertirse en «una oferta que no podrás rechazar». También será en este contexto cuando la tradicional separación entre políticas pasivas y activas de empleo empieza a difuminarse.

En la CAPV en el año 1989 se aprobó el Plan Integral de Lucha contra la Pobreza, que se concretó en la Ley 2/1990, de 3 de mayo, de Ingreso Mínimo de Inserción. Según dice su Exposición de Motivos, en la parte final del inciso I:

... el ingreso mínimo de inserción, que crea esta ley, nace de una concepción claramente avanzada, basada en el respeto a las personas y en la creencia de que la marginación no responde a razones intrínsecas, sino a factores externos que les imposibilitan salir de la situación en que se encuentran si los ciudadanos más favorecidos no ejercitan la solidaridad social. En definitiva, el ingreso mínimo de inserción, con el apoyo de las medidas sociales existentes, pretende crear las condiciones necesarias, removiendo las causas que dieron lugar a una situación no buscada por los interesados, para que los beneficiarios del mismo puedan salir de ella. Y todo ello en el convencimiento de que, aportando este mínimo de medios precisos, serán los propios interesados los que lucharán por dejar atrás su situación de pobreza en la medida en que sus capacidades lo permitan y con el apoyo de otras acciones y programas sociales dirigidos a los mismos. De acuerdo con lo arriba expresado, el ingreso mínimo de inserción no pretende crear una nueva clase pasiva, cronificando su situación, sino posibilitar su plena inserción en la vida social de Euskadi a través de la contraprestación a la que se obliga el beneficiario.

Años después, esta Ley fue derogada por la Ley 12/1998, de 22 de mayo, Contra la Exclusión Social y, según dice su Exposición de Motivos, en la parte final del inciso I:

La Ley reafirma el derecho a una renta mínima, el ingreso mínimo de inserción, que ya elevara a rango de derecho social la Ley 2/1990, de 3 de mayo. Fiel a la filosofía que la inspirara, el nuevo texto parte de considerar que la exclusión, y la pobreza como manifestación más visible de la misma y como forma más extrema de desigualdad, son hechos sociales cuya existencia y desarrollo obedecen a causas de carácter estructural, externas a los sujetos que se ven atrapados en dichos procesos. El principio de solidaridad social exige que el conjunto de los ciudadanos comparta una responsabilidad que es de todos y ponga los medios necesarios para posibilitar un acceso igualitario a las oportunidades y al ejercicio de los derechos sociales. A tales fines, la Ley prevé para los beneficiarios del ingreso mínimo de inserción su necesaria participación en programas y acciones de inserción en base a convenios de contenido negociado. Este compromiso representa para el individuo su derecho a tomar parte activa en la vida social, su inserción en el sistema y no su dependencia del mismo. Asimismo, pone de relieve la necesidad que la sociedad tiene de su participación, ga- 
rantizando, en suma, la igualdad de las partes intervinientes. La Ley incorpora, precisando su contenido, las ayudas de emergencia social. La regulación de estas prestaciones combina el intento de definir un marco global de gestión común para el conjunto de la Comunidad Autónoma con la necesidad de respetar la capacidad de decisión de los servicios sociales de base en relación a la evaluación de la necesidad en relación a estas prestaciones.

En su articulado admitió que en una misma vivienda pudieran convivir varias unidades de convivencia, en lo sucesivo UC, sin lazos familiares y, que excepcional y transitoriamente durante 2 años, determinadas UC con lazos familiares; también estableció con mayores garantías el doble derecho a la inclusión social y laboral, separado de la prestación económica.

Fruto de una ILP presentada en el Parlamento Vasco por una Carta de Derechos Sociales "Aurkitu» (1997), con el aval de más de 82.000 firmas ${ }^{4}$, fue sustituida por la Ley 10/2000, de 27 de diciembre, de Carta de Derechos Sociales que, a pesar de no recoger las principales reivindicaciones ${ }^{5}$, introdujo dos mejoras: a) el incremento del Ingreso Mínimo de Inserción, en lo sucesivo IMI, existente en aquel momento, hasta el 75\% del Salario Mínimo Interprofesional, en lo sucesivo SMI, para una UC de 1 persona, lo que supuso una subida inmediata de la prestación, en torno a un 15\%; y, b) el comienzo de la indexación de la prestación, que a partir de entonces cambió su nombre de IMI por el de

4 Los fines que presentó la promotora de la ILP por una Carta de Derechos Sociales "Aurkitu» fueron: Fomentar la participación ciudadana en la vida social, política, económica y cultural a través de comportamientos democráticos. - Reivindicar a las distintas administraciones de la Comunidad Autónoma Vasca el desarrollo de programas y disposiciones que supongan, en el campo económico, una distribución solidaria de sus respectivos presupuestos económicos, al objeto de que exista una mejor distribución del Producto Interior Bruto. - Ayudar a elevar el nivel de conciencia de la ciudadanía para que la riqueza y los recursos existentes sean mejor distribuidos. — Reivindicar de las administraciones y ciudadanía que se adopten medidas en orden a respetar todos los conceptos ecológicos y medio ambientales que hagan posible un equilibrio con la naturaleza. - Desarrollar cursos y programas con el objeto de elevar el nivel cultural de la ciudadanía vasca y favorecer las relaciones entre personas de otras comunidades. - Realizar programas, campańas, actividades, etc., en favor de los parados denunciando su situación y reivindicando mayores coberturas sociales para todos. - Participar en actos y campañas que presenten otras organizaciones fuera y dentro de la Comunidad Autónoma Vasca que sean de interés colectivo. - Presentar cuantas iniciativas legislativas populares en reconocimiento de los derechos sociales sean necesarios ante el Parlamento Vasco y las Juntas Generales de los Territorios Históricos. —-Trabajar en favor de países del llamado tercer mundo.

5 Como recuerdan De la Fuente et al. (2019) la ley abordaba los temas de la ILP, pero con un contenido muy rebajado, tanto en las consideraciones políticas como en las medidas prácticas. Así, el objetivo de garantizar el acceso al trabajo y a una renta básica que se contenía en la ILP pasa a ser de posibilitar esos derechos. El reparto del trabajo se convierte en promoción del empleo. La cuantía de renta básica que en la ILP era la del SMI pasa a ser del 75\% del SMI y se introducen requisitos restrictivos para el acceso a la misma que no se contenían en la ILP, como la certificación del estado de necesidad de la persona solicitante. La inserción laboral se establece no como un derecho, sino como una obligación para percibir la renta básica. 
Renta Básica, ligando la misma a un porcentaje del SMI, que fue creciendo en los años siguientes ${ }^{6}$.

La Ley 18/2008, de 23 de diciembre, para la Garantía de Ingresos y para la Inclusión Social ${ }^{7}$, aunque incorpora la Prestación Complementaria de Vivienda, en lo sucesivo PCV, como derecho subjetivo a una prestación para el pago de alquileres de UC perceptoras de RGI - gasto que hasta entonces corría a cuenta de las Ayudas de Emergencia Social, en lo sucesivo AES-, acarrea varios retrocesos, ya que; a) reduce a dos el número de RGI que se pueden cobrar por vivienda, con independencia del número de UC que habiten en la misma; b) aumenta los requisitos, obligaciones y, sobre todo, los controles de las personas perceptoras, introduciendo la revisión bienal de la prestación; y, c) instaura la empleabilidad como elemento fundamental del sistema, convirtiéndola en una contraprestación de la RGI, que transforma el Convenio de Inclusión, convirtiéndolo en un instrumento de expulsión de posibles receptoras.

Casi tres años después, la Ley 4/2011, de 24 de noviembre, de modificación de la Ley para la Garantía de Ingresos y para la Inclusión Social, hará más difícil para personas sin recursos el acceso a la RGI y la PCV, así como, una vez conseguidas, mantenerse en ellas, ya que, de una parte, eleva el requisito de empadronamiento y residencia de uno a tres ańos, suponiendo éste un mayor obstáculo para las personas extranjeras que no encuentran forma de empadronarse en los lugares donde residen, o que, por carecer de residencia, se les impide el acceso al padrón y, de otra parte, elimina la posibilidad de rechazar oferta alguna de empleo e implanta un ańo de penalización para quien rechace o deje de forma voluntaria un empleo.

La evolución negativa se acentúa a partir del año 2012, ya que en los Presupuestos de la CAPV de 2012 se recorta la partida de la RGI un 7\%, manteniéndose ese recorte a partir de entonces, y desaparece la indexación de la RGI al SMI, lo que ha supuesto una rebaja sustancial de la RGI, a partir de ese momento. Ese mismo año 2012, Lanbide sustituye a los servicios sociales en la gestión de la RGI y de la PCV.

Actualmente está en debate una nueva regulación, a la vez que se espera que a partir del año 2022 el Gobierno Vasco gestione el Ingreso Mínimo Vital, en lo sucesivo IMV, que aprobó el Gobierno de España mediante Real Decreto-

${ }^{6}$ Hasta llegar, en la Ley de 2008, al 88\% del SMI para una UC de 1 persona; $113 \%$ para una UC de 2 personas y $125 \%$ para una UC de 3 o más personas, en el caso de la RGI para no pensionistas; y hasta el $100 \%$ del SMI para una UC de 1 persona; $125 \%$ para una UC de 2 personas, y $135 \%$ para una UC de 3 o más personas, para el caso de las RGI de pensionistas.

7 Deroga la Ley 12/1998, de 22 de mayo, contra la Exclusión Social, así como la Ley 8/2000, de 10 de noviembre, la Ley 9/2000, de 10 de noviembre, y la Ley 4/2003, de 25 de junio, de modificación de la Ley contra la Exclusión Social. También deroga los artículos 6, 7 y 8 de la Ley 10/2000, de 27 de diciembre, de Carta de Derechos Sociales. 
ley 20/2020, de 29 de mayo, y tal como indica su Exposición de motivos, concretamente al inicio del apartado III:

Esta prestación ${ }^{8}$ nace con el objetivo principal de garantizar, a través de la satisfacción de unas condiciones materiales mínimas, la participación plena de toda la ciudadanía en la vida social y económica, rompiendo el vínculo entre ausencia estructural de recursos y falta de acceso a oportunidades en los ámbitos laboral, educativo, o social de los individuos. La prestación no es por tanto un fin en sí misma, sino una herramienta para facilitar la transición de los individuos desde la exclusión social que les impone la ausencia de recursos hacia una situación en la que se puedan desarrollar con plenitud en la sociedad. Aunque la situación de privación económica que sufren las personas a las que va dirigida esta medida esté en el origen de su situación de vulnerabilidad, la forma concreta que tomará su inclusión social variará en función de las características de cada individuo: para algunos, será el acceso a oportunidades educativas, para otros, la incorporación al mercado de trabajo o, la solución a una condición sanitaria determinada. Este objetivo de inclusión condiciona de manera central el diseño de la prestación, que, incorporando las mejores prácticas internacionales, introduce un sistema de incentivos buscando evitar la generación de lo que los expertos en política social han llamado "trampas de pobreza", esto es, que la mera existencia de prestación inhiba el objetivo de inclusión social y económica de los receptores.

Este IMV se basa en la unidad familiar y no en los individuos, estando condicionada a los recursos, por lo que, como señala Foessa (2021), el IMV ofrece una cobertura insuficiente, a lo que se suma la falta de información correcta y adecuada para iniciar el trámite de solicitud, que lleva a que sólo un $26 \%$ de los hogares en pobreza severa han conseguido realizar el mismo. Es decir, más de dos tercios de estos hogares (el 68\%) no lo han solicitado a pesar de sus escasos o nulos ingresos, por lo que únicamente el $18,6 \%$ de solicitantes en pobreza severa está cobrando el IMV o, al menos, lo tiene concedido. Hasta septiembre de 2021 el total de prestaciones concedidas asciende a 799.203 personas, beneficiando a 315.913 hogares, el $37,2 \%$ de los previstos inicialmente, llegando la cuantía media a los $436 €$ por hogar. La ratio de beneficiarios por prestación es de 2,53 personas.

Para acabar con el repaso a las tres décadas de existencia de este modelo, hago mía la conclusión de la ILP para una RBI en la CAPV, cuando en el apartado II) de la Exposición de Motivos dice:

Lo que ha fallado en estos últimos 30 años de lucha contra la pobreza en la CAPV, no ha sido la gestión de un modelo, sino el propio modelo, lo cual exige, como una necesidad perentoria de política económica y social, la implantación de otro modelo nuevo y alternativo, como se propone en esta ILP, a través de una RBI.

8 Se trata de una renta de 470 euros al mes para una persona adulta que viva sola y, cuando se trata de una unidad de convivencia, esa cantidad se incrementa en 141 euros al mes por cada persona adicional, adulta o menor, hasta un máximo de 1.034 euros al mes y, en el caso de las familias monoparentales, se añade un complemento equivalente a un $22 \%$ de las pensiones no contributivas. 


\section{Principales características de la RBI propuesta en esta ILP}

Porque hace falta otro modelo alternativo al de rentas mínimas y garantizadas vigente en esta Comunidad Autónoma, paso a explicar el contenido principal de esta ILP, que consta de una extensa Exposición de Motivos y el correspondiente texto articulado, donde se fijan su ámbito, concepto y principios, fines, requisitos, importe y varias disposiciones.

El inicio de la Exposición de Motivos anticipa su contenido, que incluye:

1) el Marco jurídico de los derechos humanos; II) la insuficiencia de las rentas de garantía de ingresos, vigentes en esta Comunidad Autónoma, para acabar con la pobreza; III) reflexiones en torno al contexto actual, y el mito del trabajo como elemento de integración social; IV) diferentes voces favorables a la implantación de la RBI, V) las características de la RBI que se propone en esta ILP. Finalmente, se incorpora el articulado con que defiende esta Iniciativa.

El Texto articulado de esta ILP propone implantar por ley una RBI, que sea un derecho en favor de toda persona con residencia efectiva en el territorio de la CAPV e inmediatamente anterior en al menos tres meses a la solicitud, consistente en una prestación monetaria mensual que le permita la satisfacción de sus necesidades básicas, sin que ello tenga como exigencia una contraprestación de ningún tipo e independientemente de su participación en el mercado de trabajo, siendo compatible con cualquier salario o prestación contributiva.

Según indica el art. 5, su importe se fijará anualmente en la Ley de Presupuestos Generales de la CAPV, aceptando el cumplimiento de los siguientes requisitos:

1. Se respetará como importe mínimo $900 €$ mensuales para una persona adulta o una menor de 18 ańos emancipada y el $30 \%$ de la cantidad que se fije anteriormente, en este caso $270 €$, si es menor de 14 años y el $50 \%$, en este caso $450 €$, si teniendo más 13 ańos no llega a los 18 años ni está emancipada.

2. ${ }^{\circ}$ Se garantizará que, anualmente el importe de la RBI del año anterior, se incrementará en el IPC registrado en la CAPV, siempre que este sea mayor que cero.

3. ${ }^{\circ}$ El importe de la RBI establecido en la Ley de Presupuestos de la CAPV, nunca podrá ser inferior al umbral de pobreza relativa de la CAPV.

Los principios básicos de la RBI, establecidos en el art. 2, son:

a) el carácter universal de la prestación económica.

b) su carácter individual.

c) el carácter no condicionado a los ingresos económicos o rentas que se tengan, así como al patrimonio, ya sean personales o familiares, sin perjuicio de que estos ingresos o patrimonio estén gravados por los impuestos correspondientes que la normativa fiscal establezca, y de que la RBI sustituya a otras prestaciones no contributivas. 
Como dice el inciso final del mismo art. 2: «La RBI tiene carácter irrenunciable, inalienable, imprescriptible e inembargable y toda cesión que se hiciera de ella, cualquiera que sea su causa, será nula».

El art. 3 señala que, mediante la creación del derecho subjetivo a la RBI, se persiguen las siguientes cuatro finalidades:

a) Incrementar el grado de autonomía y libertad real de la ciudadanía, empoderándola en las elecciones laborales, de formación y de proyectos de vida, con el fin de que faculte y estimule actitudes participativas y solidarias en actividades colectivas y sociales, que lleven a una sociedad más colaborativa.

b) Acabar con las situaciones de pobreza y las condiciones que propician su ciclo de reproducción, dando plena efectividad al derecho humano a unas condiciones de existencia dignas.

c) Superar y sustituir el sistema de rentas mínimas garantizadas y condicionadas, vigente hasta la fecha, proponiendo un sistema de prestaciones más integrado y coherente, que evite la estigmatización de aquella parte de la población que para subsistir depende total o parcialmente de las prestaciones asistenciales.

d) Permitir un reparto más justo de la riqueza, contribuyendo a una mayor cohesión social, y calidad de la democracia.

Como se ve, esta ILP pretende reforzar el estado de bienestar, sumando a los actuales pilares de la educación, sanidad, servicios sociales y vivienda, el instrumento de la RBI. De esta forma quiere hacer efectivo el derecho humano emergente proclamado en la Declaración Universal de Derechos Humanos Emergentes de Monterrey $(2007)^{9}$ que, en su art. 1, referido al Derecho a la existencia en condiciones de dignidad, establece en su apartado tercero:

3. El derecho a la renta básica o ingreso ciudadano universal, que asegura a toda persona, con independencia de su edad, sexo, orientación sexual, estado civil o condición laboral, el derecho a vivir en condiciones materiales de dignidad. A tal fin, se reconoce el derecho a un ingreso monetario periódico incondicional sufragado con reformas fiscales y a cargo de los presupuestos del Estado, como derecho de ciudadanía, a cada miembro residente de la sociedad, independientemente de sus otras fuentes de renta, que sea adecuado para permitirle cubrir sus necesidades básicas.

9 Aprobado en su forma definitiva en el Forum de las Culturas Monterrey, celebrado del 30 de octubre al 4 de noviembre de 2007, sobre un proyecto de Carta de Derechos Humanos Emergentes realizado por un comité de académicos, activistas, políticos y miembros de organizaciones internacionales organizado por el Instituto de Derechos Humanos de Cataluña y con aportaciones en el Fórum Universal de las Culturas Barcelona 2004. La Declaración constituye un programa demandado por la sociedad civil a gobiernos e instituciones en el siglo xxI. 
También se identifica con el concepto de RBI de la Basic Income Earth Network ${ }^{10}$, que afirma que una Renta Básica es «un pago en efectivo periódico que se entrega incondicionalmente a todos de forma individual, sin verificación de recursos ni requisitos de trabajo.»

Para terminar este apartado quiero referirme a la financiación, pues, la RBI requiere una gran dedicación de recursos, aunque no se deben equiparar las transferencias y los gastos. En la Exposición de Motivos se afirma que «la financiación de la RBI se establecería a través de los impuestos». En la investigación de su reciente tesis doctoral ${ }^{11}$ Bollain (2021) plantea un supuesto, el $2 \mathrm{~b}$, de modelo de renta básica individualizada, de cuantía igual al umbral de la pobreza de la CAPV para las personas mayores de edad que, según la Encuesta de Condiciones de Vida, en lo sucesivo ECV, de 2019, se sitúa en los $12.577 €$ y un $20 \%$ del mismo, es decir, 2515,4€, para las personas menores de 18 años. En este modelo las pensiones y las prestaciones por debajo de la cuantía de la RBI no son consideradas como ahorro y, por lo tanto, dicho montante de 6.964.519.172€ no es absorbido para la financiación de la RBI, por lo que el coste bruto de la RBI que debe financiarse a través de la reforma fiscal es de 23.654.122.890€. En dicho montante se incluye la introducción de una cláusula de compensación para que ningún hogar por debajo de la decila 8 reduzca sus ingresos, lo que añade un coste de 274.314.493€. Para la financiación de todo ello es suficiente un tipo único del IRPF del 71,55\%, pero Bollain propone otro de 5 punto menos, es decir, al $66,55 \%$, lo que lleva a que 2.127.996.929€ de la financiación deba ser cubierto mediante fuentes externas al IRPF, lo que, según dice, podría hacerse:

a) Con el Impuesto sobre Sociedades, que en el año 2018 en la Unión Europea se situó en 2,66\% del PIB. En la CAPV, en el 1,64\%. Es decir, igualarse respecto a la presión fiscal ejercida sobre el Impuesto sobre Sociedades con la media de la Unión Europea supondría incrementar la recaudación en $809.000 .000 €$ —un $62 \%$ más de lo que se recauda actualmente-.

b) Con un gravamen del $8 \%$ a las 15 personas más ricas de la CAPV, que en 2018 tenían un patrimonio igual a 9.820 millones de euros, lo que permite recaudar anualmente hasta $785.600 .000 €^{12}$.

10 Esta Red internacional señala que las características de la renta básica, son: 1) Periódico: se paga a intervalos regulares (por ejemplo, cada mes), no como una subvención única; 2) Pago en efectivo: se paga en un medio de cambio apropiado, lo que permite a quienes lo reciben decidir en qué lo gastan. Por lo tanto, no se paga ni en especie (como alimentos o servicios) ni en vales dedicados a un uso específico; 3) Individual: se paga de forma individual y no, por ejemplo, a los hogares; 4) Universal: se paga a todos, sin prueba de medios; 5) Incondicional: se paga sin el requisito de trabajar o demostrar voluntad de trabajar.

${ }^{11}$ El 25 de noviembre de 2021 fue defendida en la sede de la Facultad de Economía y Empresa de la UPV/EHU, en Bilbao.

12 World Inequality Lab (2021), en el Informe sobre la desigualdad en el mundo 2022 revisa varias opciones de políticas para redistribuir la riqueza, incluyendo una tabla donde presenta ganan- 
c) Con un incremento de la imposición ambiental que, si se iguala a la media de la Unión Europea, que en 2018 fue del 2,39\% del PIB, equivaldría a recaudar un $0,65 \%$ sobre el PIB adicional anualmente, es decir, 468.192.140€ adicionales.

d) Con una disminución del fraude fiscal, dado que la economía sumergida en la CAPV, de 2010 a 2014, fue del 17,4\% del PIB, mientras que la media de la Unión Europea se quedó en un 16,5\% del PIB, de forma que, si se redujese en la CAPV en 0,9 puntos porcentuales para igualarse a la media europea, supondría ingresar 648.266.040€ adicionales.

La suma de estas fuentes externas reportaría 2.711.058.180€ adicionales, superando el objetivo trazado.

La financiación de la RBI plantea la necesidad de una reforma fiscal. Por ello quiero terminar este punto recordando las Observaciones Finales del Comité de Derechos Económicos, Sociales y Culturales de Naciones Unidas, en lo sucesivo Comité DESC ( 2018), al 6. Informe de España sobre el cumplimiento del Pacto Internacional de los Derechos Económicos, Sociales y Culturales de 1966, en lo sucesivo PIDESC, donde en relación a la política fiscal, señala ${ }^{13}$ :

15. Preocupa al Comité que la política fiscal no sea suficientemente efectiva para hacer frente a los efectos adversos de la creciente desigualdad social en el Estado parte, debido al peso excesivo de los impuestos indirectos en los ingresos del Estado y a que ciertas transferencias no llegan a las poblaciones que deberían beneficiarse de ellas. Asimismo, le preocupa que la aplicación de exenciones tributarias y la falta de control adecuado al fraude fiscal estén afectando la capacidad del Estado parte para cumplir con su obligación de movilizar la mayor cantidad de recursos disponibles para hacer plenamente realidad los derechos económicos, sociales y culturales en beneficio de las personas y grupos desfavorecidos y marginados (art. 2, párr. 1).

16. El Comité recomienda al Estado parte que:

a) Realice una evaluación exhaustiva, con participación de los actores sociales, de los efectos de su política fiscal en los derechos humanos, que entre otros incluya un análisis de las consecuencias distributivas y la carga impositiva de diferentes sectores, así como de los grupos marginados y desfavorecidos.

b) Vele por que su sistema fiscal sea socialmente justo y con un mayor efecto redistributivo.

cias de ingresos que provendrían de un modesto impuesto progresivo sobre el patrimonio a los multimillonarios globales, que dado el gran volumen de concentración de la riqueza, generaría ingresos importantes para los gobiernos.

13 El Comité examinó el sexto informe periódico de España (E/C.12/ESP/6) en sus sesiones 16. ${ }^{\mathrm{a}}$ y 17. ${ }^{\mathrm{a}}$ (véanse E/C.12/SR.16 y 17), celebradas los días 21 y 22 de marzo de 2018. En su 28. ${ }^{\mathrm{a}}$ sesión, celebrada el 29 de marzo de 2018, aprobó las observaciones finales. 
c) Vele por optimizar la recaudación de impuestos, con el fin de aumentar los recursos disponibles para hacer realidad los derechos económicos, sociales y culturales.

d) Evalúe periódicamente la pertinencia de las exenciones tributarias.

e) Tome medidas estrictas para combatir el fraude fiscal, en particular el cometido por empresas y personas con grandes patrimonios.

\section{La RBI es un instrumento cada vez más reclamado}

Es muy destacable el creciente interés y apoyos que la RBI está consiguiendo en los últimos años. Hace pocos meses, el Gobierno catalán ha creado la Oficina del Plan Piloto para implementar la Renta Básica Universal y nombrado a D. Sergi Raventós Panyella como Jefe de la misma ${ }^{14}$. También el apartado IV de la Exposición de Motivos de esta ILP se hace eco de ello y enumera distintas voces favorables a la RBI. Así,

- La Asamblea Parlamentaria del Consejo de Europa (2018) aprobó una resolución del Comité de Asuntos Sociales, Salud y Desarrollo Sostenible $(2018)^{15}$ en la que, junto a otros acuerdos, animó a que sus 47 Estados miembros impulsaran actuaciones que permitieran comprobar si la Renta Básica Universal, permitía avanzar en el logro de los derechos y la cohesión social.

— Investigadores de la Organización Internacional del Trabajo (Ortiz, I. et al., 2018) propusieron a los gobiernos reflexionar detenidamente sobre una forma efectiva de integrar la Renta Básica Universal en el Sistema de Protección Social.

- Wignaraja (2020), subdirectora regional del Programa de las Naciones Unidas para el Desarrollo de Asia y el Pacífico, que el 20 de mayo y el 17 de julio de dicho año, destacó la necesidad de poner en marcha la renta básica universal.

- El Papa Francisco (2020), cree que es hora de explorar conceptos como el ingreso básico universal.

- El Consejo General del Trabajo Social (2020) demanda que la Renta Básica sea la meta del camino iniciado con el Ingreso Mínimo Vital ${ }^{16}$.

— Profesionales sociales y educativos de España (2020) reclamaron una Renta Básica Universal, convencidos de que es una política imprescindible y necesaria para garantizar el derecho a una vida material digna para las personas $^{17}$.

${ }_{14}$ Publicado en el Diario Oficial de la Generalitat de Catalunya n. ${ }^{\circ} 8499$, del 10 de septiembre de 2021.

${ }^{15}$ El Informe de la Comisión fue publicado el 6 de enero de 2018 y la votación de la Asamblea se realizó el 23 de enero de 2018.

${ }_{16}$ El informe Trabajo Social ante la garantía de rentas, fue aprobado el 21 de mayo de 2020.

17650 profesionales firmaron el Manifiesto por una Renta Básica Universal en junio de 2020. 
— Profesionales del sector cultural en España (2020), firmaron un Manifiesto en defensa de la renta básica universal e incondicional como la mejor política cultural posible ${ }^{18}$.

— Organizaciones feministas de España (2020), firmaron un documento a favor de la Renta Básica.

- Investigadoras/es y profesoras/es del ámbito académico, universitario y de centros de investigación del País Vasco (2020) firmaron un documento donde abogan por el establecimiento de una renta básica universal ${ }^{19}$.

A este elenco, quiero añadir la reciente alocución del Papa Francisco (2021), cuando dijo ${ }^{20}$ :

Porque es tiempo de actuar.

Muchas veces, me dicen: «Padre, estamos de acuerdo, pero, en concreto, ¿qué debemos hacer?» Yo no tengo la respuesta. Por eso debemos soñar juntos y encontrarla entre todos. Sin embargo, hay medidas concretas que, tal vez, permitan algunos cambios significativos. Son medidas que están presentes en vuestros documentos, en vuestras intervenciones y que yo he tomado muy en cuenta; sobre las que medité y consulté a especialistas. En encuentros pasados hablamos de la integración urbana, la agricultura familiar, la economía popular. A éstas, que todavía exigen seguir trabajando juntos para concretarlas, me gustaría sumarle dos más: el salario universal y la reducción de la jornada de trabajo. Un ingreso básico (el IBU) o salario universal para que cada persona en este mundo pueda acceder a los más elementales bienes de la vida. Es justo luchar por una distribución humana de estos recursos. Y es tarea de los gobiernos establecer esquemas fiscales y redistributivos para que la riqueza de una parte sea compartida con la equidad, sin que esto suponga un peso insoportable, principalmente para la clase media — generalmente en estos conflictos es la que más sufre- . No olvidemos que las grandes fortunas de hoy son fruto del trabajo, la investigación científica y la innovación técnica de miles de hombres y mujeres a lo largo de generaciones. La reducción de la jornada laboral es otra posibilidad: el ingreso básico es una posibilidad, la otra, es la reducción de la jornada laboral. Y hay que analizarla seriamente. En el siglo xIx los obreros trabajaban doce, catorce, dieciséis horas por día. Cuando conquistaron la jornada de ocho horas no colapsó nada, como algunos sectores preveían. Entonces, insisto, trabajar menos para que más gente tenga acceso al mercado laboral, que es un aspecto que necesitamos explorar con cierta urgencia. No puede haber tantas personas agobiadas por el exceso de trabajo y tantas otras agobiadas por la falta de trabajo.

Considero que son medidas necesarias, pero desde luego no suficientes. No resuelven el problema de fondo, tampoco garantizan el acceso a la tierra, techo y trabajo en la cantidad y calidad que los campesinos sin tierra, las familias sin un techo seguro y los trabajadores precarios merecen. Tampoco van a resolver los enormes de-

18 Más de un millar de profesionales del sector cultural en España que, en mayo de 2020, firmaron el Manifiesto Gente que trabaja en cultura, por una renta básica universal e incondicional

19 Fueron 764 investigadoras/es y profesoras/es, al que se han sumado otras 3.213 personas y 191 Organizaciones vascas.

20 Fue el 16 de octubre de 2021 en el IV Encuentro con los Movimientos Populares. 
safíos ambientales que tenemos por delante, pero quería mencionarlas, porque son medidas posibles y marcarían un camino positivo de orientación.

Es bueno saber que en esto no estamos solos. Las Naciones Unidas intentaron establecer algunas metas a través de los llamados objetivos de desarrollo sostenible, pero, lamentablemente, desconocidas por nuestros pueblos y las periferias, lo que nos recuerda la importancia de compartir y comprometer a todos en esta búsqueda común.

También en el ámbito investigador, concretamente dentro del marco de la UPV/EHU, ha habido en los últimos años un continuo trabajo alrededor de la RBI, que probablemente fue potenciado por la firma, el 22 de febrero de 2016, de un Convenio de Colaboración entre la UPV/EHU y la Red Renta Básica, que ha impulsado la realización de muchos Trabajos Finales de Grado y de Máster, así como de tesis, amén de múltiples actividades entre las que cabe destacar que en septiembre de 2016, en víspera de las elecciones autonómicas, se celebrara en el Aula Magna de Leioa una Mesa Redonda con representantes de los partidos políticos representados en el Parlamento Vasco, que debatieron sobre la Renta Básica y la Juventud; o que en el mismo mes Belaustegi L. et al. (2016) llevaran a cabo una Encuesta entre personas que trabajan o estudian en la UPV/EHU, a la que respondieron 3.004 personas, mostrando una clara mayoría favorable a la implementación de la RBI; o que se celebrase el XVI Simposio de la Renta Básica (Asociación Red Renta Básica: 2016) ${ }^{21}$; o que en la UPV/EHU (2021) esté finalizándose el Proyecto Estratégico Gaztebi (Gazte Basic Income), que incluye la opinión del alumnado de la UPV/EHU en torno a la RBI.

La propia presentación de la ILP en la CAPV demuestra el apoyo a la RBI, como lo acreditan las de momento 77 organizaciones que públicamente han mostrado su adhesión a la iniciativa ${ }^{22}$.

\section{Poner fin a la pobreza}

Al analizar la EPDS observamos que en el año 1986 se realizan los primeros registros respecto al número de personas en situación de pobreza severa, que abarca los hogares cuyos ingresos están por debajo del $40 \%$ de la renta mediana en la CAPV, siendo 69.578 personas, un 3,3\% de la población. Para el año 2008 este número se había reducido en un 4,4\%, hasta las 66.539 personas.

${ }^{21}$ Se celebró en noviembre de 2016, en la sede de la Facultad de Economía y Empresa de la UPV/EHU, en Sarriko.

${ }^{22}$ Es muy amplio el espectro de entidades que apoyan, desde sindicatos a entidades como Cáritas y otras muchas vinculadas con la defensa de los derechos humanos y los movimientos sociales. 
A partir del año 2008 se da el mayor aumento, incrementándose un 57,5\% en tan solo 6 años y llegando hasta las 104.943 personas en el año 2014. Los datos del año 2020 permiten corroborar esta tendencia al alza, habiendo un crecimiento de un $26,87 \%$ respecto a 2014 y de un $98,64 \%$ respecto a 2008 , con 132.173 personas en situación de pobreza severa ${ }^{23}$.

Esto significa una violación de la legalidad en materia de derechos humanos, pues, desconoce el derecho de toda persona a un nivel de vida adecuado para sí y su familia, incluso alimentación, vestido y vivienda adecuados, y a una mejora continua de las condiciones de existencia, tal como es reconocido en el art. 11.1 del Pacto Internacional de los Derechos Económicos, Sociales y Culturales (1966), en lo sucesivo PIDESC, que forma parte del ordenamiento interno español tras haber sido ratificado por España en el año 1977.

Hay que tener en cuenta que conforme al artículo 2.1 del PIDESC:

Cada uno de los Estados Partes en el presente Pacto se compromete a adoptar medidas, tanto por separado como mediante la asistencia y la cooperación internacionales, especialmente económicas y técnicas, hasta el máximo de los recursos de que disponga, para lograr progresivamente, por todos los medios apropiados, inclusive en particular la adopción de medidas legislativas, la plena efectividad de los derechos aquí reconocidos.

Y según acuerda, en la Observación General 3, el Comité DESC ${ }^{24}$, se debe dar a la frase "por todos los medios apropiados» su significado pleno y natural. Añade:

Si bien cada Estado Parte debe decidir por sí mismo qué medios son los más apropiados de acuerdo con las circunstancias y en relación con cada uno de los derechos contemplados, la "propiedad" de los medios elegidos no siempre resultará evidente. Por consiguiente, conviene que los Estados Partes indiquen en sus informes no sólo las medidas que han adoptado sino también en qué se basan para considerar tales medidas como las más «apropiadas» a la vista de las circunstancias. No obstante, corresponde al Comité determinar en definitiva si se han adoptado o no todas las medidas apropiadas ${ }^{25}$.

${ }^{23}$ El último Informe de la Fundación de Estudios Sociales y de Sociología Aplicada —Foessa(2019) revela que en el ańo 2018 el número de personas en exclusión social en el País Vasco era de 334.000 personas, el 15,2\% de la población, y aquellas personas que se encontraban en la exclusión más severa representaban unas 194.000 personas, es decir, el 8,8\% de la sociedad vasca.

${ }^{24}$ Es un órgano compuesto de 18 expertos independientes que supervisa la aplicación del PIDESC por sus Estados partes. El Comité se creó en virtud de la Resolución ECOSOC 1985/17, del 28 de mayo de 1985, para llevar a cabo las funciones de seguimiento asignadas al Consejo Económico y Social de las Naciones Unidas, en la Parte IV del PIDESC.

25 Del parágrafo 4 de la Observación General 3, aprobado en el Quinto período de sesiones, en 1990. 
Y, el carácter apropiado de un instrumento depende, en última instancia, de su eficacia para la materialización de los derechos sociales. Igualmente, para que cada Estado Parte pueda atribuir su falta de cumplimiento de las obligaciones mínimas a una falta de recursos disponibles, debe demostrar «que ha realizado todo esfuerzo para utilizar todos los recursos que están a su disposición en un esfuerzo por satisfacer, con carácter prioritario, esas obligaciones mínimas» ${ }^{26}$.

Bollain (2021) ha analizado las cinco principales limitaciones que contienen los programas de rentas mínimas y condicionadas, que como hemos visto es el modelo vigente desde 1989 en la CAPV, a saber: restricciones presupuestarias, cobertura insuficiente, estigmatización de las personas beneficiarias, costes de administración y trampa de la pobreza. A continuación, resumo su contenido principal.

\subsection{Restricciones presupuestarias}

Las rentas mínimas son programas que cubren un pequeño porcentaje de población, ya que sus presupuestos son muy limitados. Incluso en los casos en que se reconoce el carácter de derecho subjetivo como, por ejemplo, la Renta de Garantía de Ingresos de Euskadi, esta sufrió importantes modificaciones en el año 2011, con el incremento del tiempo mínimo necesario de empadronamiento para poder acceder al derecho pasando de 1 a 3 años, la limitación a un máximo de 2 prestaciones por vivienda independientemente del tamaño de ésta o del número de personas residentes en la misma o la realización de un recorte del 7\% en las prestaciones, que no ha sido revertido hasta el año 2020. A día de hoy, se mantiene otro recorte en su cuantía tras desvincular anualmente y a través de la Ley de Presupuestos Generales de la Comunidad Autónoma de Euskadi la cuantía de la RGI de la de Salario Mínimo Interprofesional, como dicta la Ley 18/2008, de 23 de diciembre, para la Garantía de Ingresos y para la Inclusión Social.

\subsection{Cobertura insuficiente}

Conocida como tasa de no-aceptación, corresponde a las personas que no perciben los subsidios condicionados a los cuales tienen derecho. Frente a lo que pudiera creerse, las investigaciones de Hernanz et al. (2004) concluyen que la tasa de no-aceptación de las prestaciones sociales, en general, suele ser muy alta en los países de la OCDE. En especial, ésta es mayor cuando hace referencia a los programas de asistencia social condicionada, entre los que se encuentran las rentas mínimas y cuyo porcentaje varía entre el $20 \%$ y el $60 \%$ depen-

26 Inciso final del parágrafo 10 de la Observación General 3, del Comité DESC. 
diendo del país, ya que algunos programas están mejor diseñados que otros y, en el caso de la CAPV, la RGI se ha mantenido desde el ańo 2008 en una tasa de no-aceptación que ha fluctuado entre el $27,1 \%$ del año 2014 hasta el 36,4\% del año 2008, pasando por el 30,7\% en 2016 y 2018 o el 29,8\% en 2020, según la EPDS del Gobierno Vasco (2021). Aunque las causas son múltiples, es un hecho que hay muchas objeciones a reclamar subsidios condicionados, siendo destacable la estigmatización que genera.

\subsection{Estigmatización de las personas beneficiarias}

Los sistemas de rentas mínimas son, a través de los mecanismos de control, uno de los más claros ejemplos de invasión en las vidas de las personas por parte de la Administración Pública. Este control continuo - desde el momento en que se solicita la prestación hasta el momento en que se deja de recibirla-e invasivo contribuye a una mayor estigmatización de las personas - potencialmente- beneficiarias, quienes tienen que "desnudarse» y actuar como "sumisas suplicantes» de una renta mínima ante la burocracia estatal.

Cabe hablar de dos formas de estigmatización: de integridad y de tratamiento. La estigmatización de integridad se basa en las preocupaciones sobre la posibilidad de estereotipación negativa — personas vagas, perezosas, deshonestas...- que se asocia a los subsidios condicionados y que afecta a la imagen que la persona - potencialmente- beneficiaria tiene sobre sí misma. La estigmatización de tratamiento, por el contrario, se basa en cómo las demás personas ven y actúan ante las personas beneficiarias que, una vez estigmatizadas, son etiquetadas como responsables de su destino Weiner et al. (1988).

\subsection{Costes de administración}

Como señaló Van Parijs (2006), en la era de la transferencia tecnológica y con una administración razonablemente bien gestionada, la mayor parte del coste administrativo asociado de los programas de rentas mínimas va dirigido al coste de la información y al coste del control. Es decir, aquél destinado a informar a la ciudadanía de sus derechos y a verificar que las personas - potencialmente- beneficiarias de dichos derechos realmente son elegibles para acceder a los mismos. Además, un programa de subsidios condicionados va a requerir un control periódico de las rentas o activos que pueda tener una unidad familiar beneficiaria para comprobar su legitimidad de acceso al programa, por lo que estos costes aumentarán cuanto mayor sea el control que la administración realice a lo largo del proceso.

En la CAPV, la respuesta del Gobierno Vasco a la iniciativa parlamentaria registrada el 11 de mayo de 2018 por Bollain, nos indica que alrededor del $6,34 \%$ del dinero destinado al sistema de renta de garantía de ingresos se utiliza 
para gasto del personal de la administración y para trámites administrativos, de control, mejora y evaluación.

\subsection{Trampas de la pobreza}

La imposibilidad de recibir al mismo tiempo dos rentas y/o de sobrepasar un determinado nivel de ingresos, por incompatibilidad expresa del programa de rentas mínimas en cuestión, nos deriva a la trampa de la pobreza. La trampa de la pobreza es definida por Raventós (2000), como «la penalización que comporta el aceptar por parte del beneficiario de un subsidio condicionado un trabajo remunerado», siendo dicha penalización la cuantía reducida de la prestación condicionada.

Mientras la no acumulabilidad en los subsidios desincentiva la búsqueda activa de empleo, puede, en cambio, incentivar el pequeño fraude fiscal. Además, muchas veces los beneficios a corto plazo de obtener dos rentas, una a través de la prestación y otra a través de una actividad realizada en el ámbito del trabajo sumergido, tienen una mayor influencia que los perjuicios a medio y largo plazo, donde el trabajo sumergido jamás se tendrá en cuenta a la hora de calcular una prestación de desempleo o una pensión de jubilación, como indicó el propio Raventós (2007).

Frente a ello, una RBI supera estas limitaciones de las rentas mínimas condicionadas gracias a los principios de universalidad, incondicionalidad y acumulabilidad de rentas. Y la propuesta de RBI en esta ILP acaba totalmente con la pobreza material, dado que el art. 5 establece que su importe «nunca podrá ser inferior al umbral de pobreza relativa de la CAPV».

\section{Generar salud y bienestar}

En las diferentes experiencias piloto de RBI se ha comprobado esta relación favorable en la salud y bienestar. Una de las más conocidas fue el MIN$\mathrm{COME}^{27}$, que durante cuatro años tuvo lugar en la pequeña ciudad canadiense de Dauphin, a mediados de la década de 1970, donde entre los beneficios estadísticamente significativos para quienes participaron en el proyecto se incluye la disminución de los contactos con médicos en relación con la salud mental y de los ingresos hospitalarios por accidente y lesión. Una vez concluido el experi-

27 Mincome: acrónimo formado por las palabras minimum e income. Fue Evelyn Forget, profesora de la Universidad de Manitoba, quien oyó hablar por primera vez de estos documentos en 2004. Los buscó durante cinco años, hasta que en 2009 los encontró en el Archivo Nacional de Canadá. 
mento, estos beneficios en materia de salud pública desaparecieron. Como escribió Painter $(2016)^{28}$ :

Pese a que el estudio de Dauphin solamente incluyó a los habitantes más pobres de una pequeña ciudad, si partimos de que revela un vínculo causal entre una mayor disponibilidad de dinero y la mejora de la salud, cabe suponer que habrían intervenido tres efectos. En primer lugar, la propia cantidad de dinero disponible habrá reducido directamente la desigualdad económica. En segundo lugar, el carácter incondicional del pago habrá reducido la inseguridad de los ingresos. Y, en tercer lugar, existe un multiplicador social positivo por el que los comportamientos positivos asociados a una mayor seguridad económica suelen reforzarse recíprocamente; por ejemplo, aumenta el número de adolescentes que no abandonan la escuela porque ven que sus compańeros tampoco lo hacen. En conjunto, estos efectos podrían indicar que la inseguridad económica es un vector clave por el que la desigualdad agrava el estado de salud de los más desfavorecidos.

Naciones Unidas (2021), en el Informe de los Objetivos de Desarrollo Sostenible, referido a este 3. ${ }^{\circ}$ ODS, encontró que cientos de millones de personas volvieron a caer en la pobreza extrema y el hambre crónica en 2020, lo que representa el primer aumento en la tasa mundial de pobreza extrema en más de 20 años. Concretamente en el apartado COVID-19 se denuncia que está amplificándose las desigualdades en salud. Dice así:

El COVID-19 afecta de manera desproporcionada a los ancianos, los pobres, los refugiados y los migrantes, y a una amplia gama de grupos vulnerables debido a sus circunstancias específicas de salud y socioeconómicas, las malas condiciones de vida y la falta de acceso a una atención de salud pública de alta calidad. Además, los efectos colaterales de la pandemia resultantes de la recesión económica mundial, el aislamiento social y las restricciones de movimiento afectan de manera desigual a quienes ya están marginados.

Personas mayores: los datos nacionales disponibles desglosados por edad mostraron que las personas de 65 años o más representaban cerca del 80 por ciento de todas las muertes por COVID-19, aunque solo el 14 por ciento de los casos confirmados de COVID-19 correspondían a ese grupo de edad.

Los pobres: antes de la pandemia, se estimaba que 927 millones de personas, o el $12,7 \%$ de la población mundial, realizaban pagos directos de atención médica que representaban más del $10 \%$ de sus presupuestos familiares. Esto empujó a casi $90 \mathrm{mi}$ llones de personas por debajo de la línea de pobreza extrema. Con el aumento de la pobreza debido a la pandemia, el gasto de bolsillo en salud probablemente representará una amenaza aún mayor para los pobres que el gasto en otros elementos esenciales, como alimentos y educación.

Refugiados y migrantes: la pandemia ha empeorado las ya angustiosas condiciones de vida y de salud de los refugiados y migrantes. Alrededor del 5 por ciento de los

${ }^{28}$ Anthony Painter es director del Action and Research Centre, de Londres. 
encuestados no buscaron atención médica incluso cuando tenían síntomas de COVID-19. Las principales razones citadas fueron la insuficiencia de recursos financieros, el temor a la deportación y la falta de atención médica o la falta de derecho a dicha atención.

Personas que viven en regiones en desarrollo: el acceso equitativo a las vacunas, con un enfoque en la protección de las poblaciones prioritarias, incluidos los trabajadores de la salud y los que están en mayor riesgo, es una de las medidas más importantes que se podrían tomar para mitigar los impactos económicos y en la salud y poner fin a la pandemia. control. Al 17 de junio de 2021, se habían administrado en todo el mundo cerca de 2.400 millones de dosis de vacuna COVID-19. Sin embargo, existen grandes desigualdades en la distribución: por cada 100 personas, se administraron alrededor de 68 vacunas en Europa y América del Norte, en comparación con menos de 2 en el África subsahariana.

Ante ello, el Programa de las Naciones Unidas para el Desarrollo, en lo sucesivo PNUD, (2020) ha descubierto que la renta básica temporal puede ayudar a proteger a las poblaciones vulnerables de los peores efectos de las crisis de salud y costaría a la mayoría de los países de bajos ingresos mucho menos del $1 \%$ de su PIB por mes, tal como lo dijo Dhaliwal $(2020)^{29}$. teado $^{30}$ :

En el caso de la CAPV, investigadoras e investigadores (2021) han plan-

Analizar los mecanismos necesarios para implementar una Renta Básica Universal en tiempos de pandemia. Abrir e impulsar una amplia conversación pública sobre las posibilidades de hacer avanzar los actuales sistemas de garantía de rentas en la dirección de un sistema de cobertura universal e incondicional, según el modelo de la renta básica universal.

No hay duda de que para conseguir salud y bienestar es preciso una mejora material, que impida caer en situación de pobreza y de exclusión. La RBI, por ser una medida ex ante, se adelanta a las carencias y a la enfermedad, lo que no consiguen los subsidios condicionados, que ofrecen una ayuda ex post a personas que se encuentran ya sufriendo una situación de necesidad.

29 Es directora del Grupo de Salud, Oficina de Apoyo de Políticas y Programas del PNUD y lo escribió en su bloc del PNUD, el 18 de noviembre de 2020.

30 Son 34 prestigiosas investigadoras e investigadores, y la mención aparece en la pág. 49 del $L i$ bro Blanco de la Covid19. 


\section{Afrontar la creciente desigualdad}

Es un fenómeno global, tal como nos ha mostrado World Inequality Lab (2021) en su Segunda Conferencia Mundial sobre la Desigualdad ${ }^{31}$. Cabe destacar los datos siguientes:

La desigualdad de ingresos varía mucho entre las regiones del mundo. Es el más bajo en Europa y el más alto en Oriente $\mathrm{Medio}^{32}$. En las últimas décadas, la desigualdad de ingresos ha aumentado en casi todos los países, pero a diferentes velocidades, lo que sugiere que las instituciones y las políticas son importantes para dar forma a la desigualdad. La divergencia en los niveles de desigualdad ha sido particularmente extrema entre Europa Occidental y Estados Unidos, que tenían niveles similares de desigualdad en 1980, pero que hoy se encuentran en situaciones radicalmente diferentes. Si bien la participación de ingresos del 1\% superior estaba cerca del $10 \%$ en ambas regiones en 1980, aumentó solo ligeramente al 12\% en 2016 en Europa Occidental, mientras que se disparó hasta el $20 \%$ en los Estados Unidos. Mientras tanto, en los Estados Unidos, la participación del ingreso del 50\% inferior disminuyó de más del $20 \%$ en 1980 al $13 \%$ en 2016.

¿Cómo ha evolucionado la desigualdad en las últimas décadas entre los ciudadanos del mundo? Proporcionamos las primeras estimaciones de cómo se ha distribuido el crecimiento del ingreso mundial desde 1980 en la totalidad de la población mundial. De ese crecimiento, el $1 \%$ de los que más ganan a nivel mundial ha captado el doble que el $50 \%$ de las personas más pobres. No obstante, el $50 \%$ inferior ha disfrutado de importantes tasas de crecimiento. La clase media mundial (que contiene a todos los grupos de ingresos más pobres del $90 \%$ en la UE y los Estados Unidos) se ha reducido ${ }^{33}$.

Pero la desigualdad también es local y está muy presente en la CAPV, como señala la información de la última EPDS (Gobierno Vasco, 2021: 103-107):

El desarrollo de la Gran Recesión vino acompañado en el periodo 2012-2014 por un significativo repunte al alza de la desigualdad. Entre 2014 y 2016, sin em-

${ }^{31}$ Se celebró los días 7 y 8 de diciembre de 2021, de acuerdo al programa disponible en https:// wid.world/document/second-world-inequality-conference-program-v3/

32 La desigualdad dentro de las regiones del mundo varía enormemente. En 2016, la proporción del ingreso nacional total representada solo por el $10 \%$ de los principales ingresos de esa nación (el $10 \%$ de los ingresos principales) fue del $37 \%$ en Europa, $41 \%$ en China, $46 \%$ en Rusia, $47 \%$ en EE. UU. Y Canadá, y alrededor del 55\% en África subsahariana, Brasil e India. En el Medio Oriente, la región más desigual del mundo según nuestras estimaciones, el 10\% superior captura el $61 \%$ del ingreso nacional.

33 El aumento de la desigualdad global no ha sido constante. Si bien la participación del $1 \%$ en los ingresos más altos del mundo aumentó del 16\% en 1980 al 22\% en 2000, luego descendió ligeramente al $20 \%$. La participación en los ingresos del $50 \%$ más pobre del mundo ha oscilado alrededor del 9\% desde 1980. La ruptura de la tendencia después de 2000 se debe a una reducción en la desigualdad de ingresos promedio entre países, ya que la desigualdad dentro de los países ha seguido aumentando. 
bargo, la recuperación del empleo, además de la emigración de colectivos menos favorecidos, contribuía a recortar una parte significativa del repunte alcista mencionado. Esta línea positiva se rompe entre 2016 y 2020, un periodo en el que los indicadores de desigualdad se sitúan claramente al alza en Euskadi, de forma aún más intensa entre 2018 y 2020.

En lo relativo al coeficiente de Gini, este indicador cambiaba claramente de sentido en su evolución entre 2012 y 2014. Después de caer de manera continuada hasta 2012, pasando de 28,0 en 1996 a 25,2 en 2008, y estabilizarse en 25,3 en 2012, se mostraba al alza en 2014 para alcanzar en dicho año un 27,1. Tras reducirse en 2016 a 25,8 , en 2018 el coeficiente de Gini vuelve a retomar la tendencia alcista para alcanzar un 26,7 en 2018 y un 28,2 en 2020.

Si se obvia el año 2014, marcado por un aumento en cierta forma extraordinario, es relevante constatar que, tras el periodo de caída del indicador entre 1996 y 2008, desde el 25,2 de 2008 parece iniciarse en realidad un periodo de incremento tendencial de la desigualdad que lleva al 28,2 de 2020, el nivel más elevado en el Gini de Euskadi desde 1996. En esta dirección, el último bienio supone un relanzamiento de la desigualdad. En este sentido, el incremento de 1,5 puntos en el coeficiente entre 2018 y 2020 es uno de las más elevados desde 1996, sólo superado por los 1,8 puntos de 2012 a 2014 .

La tendencia es similar en lo relativo a la ratio que relaciona los ingresos del $20 \%$ más rico de la población de la CAPV con los correspondientes al $20 \%$ más desfavorecido. En este caso, la ratio se reduce de 4,2 en 1996 a 3,6 en 2008. Repunta a partir de entonces: primero ligeramente, con un 3,7 en 2012, y posteriormente de forma más intensa hasta situarse en un 4,1 en 2018. En 2020, el indicador llega a 4,4, de nuevo en niveles históricamente máximos, incluso por encima del 4,2 de 1996 y de 2014. Entre 2012 y 2014, la dinámica más preocupante correspondía al indicador relativo a la parte del total de ingresos de la población que llega al 10\% de personas con menos recursos de la CAPV. Después de avanzar del 3,55\% de 2000 al 3,88\% de 2008, el indicador caía al 3,75\% en 2012 y al 3,41\% en 2014. Aunque remontaba al 3,48\% en 2016, el indicador mostraba una nueva reducción en 2018, con un $3,35 \%$. La tendencia se prolonga en 2020, con una nueva caída que lleva la proporción analizada al 3,18\%, el nivel más bajo del periodo 1996-2020.

El registro de 2020 se sitúa 0,70 puntos porcentuales por debajo del máximo que se había llegado a alcanzar en 2008 , con un cambio de tendencia que resulta especialmente nítido entre 2012 y 2014 (con una caída de 3,75\% a 3,41\%, -0,34 puntos porcentuales). Incluso la mejora de 3,48\% de 2016 se mantiene más cerca de las cifras de 2014 y 2018 (3,41\% y 3,35\%) que de las habitualmente registradas entre 1996 y 2012, siempre iguales o superior al 3,55\%. En este proceso de reducción del indicador, la caída de 2018-2020 supone la segunda caída en importancia desde 1996 (-0,17 puntos porcentuales entre el 3,35\% de 2018 y el 3,18\% de 2020). El deterioro que se consolida en el indicador relativo al peso del $10 \%$ de personas con menos recursos de la CAPV en 2020.

La única excepción a esta dinámica de crecimiento prácticamente generalizada de los ingresos entre 2008 y 2020 corresponde al 10\% más pobre dentro de la sociedad. Así, en este grupo de población se observa una reducción de $-9,2 \%$ en los ingresos medios netos a precios constantes en este periodo 2008-2020. La tendencia fuertemente descendente de los ingresos se ve compensada, sin embargo, de forma muy 
destacada por la acción del sistema RGI/PCV/AES. Sin la acción de este sistema de protección, la caída de ingresos medios en este $10 \%$ más desfavorecido en la distribución de ingresos (Decila 1) habría sido de $-21,3 \%$.

El sistema también contribuye de forma positiva en el segundo grupo más desfavorecido (Decila 2). Este grupo, que ve aumentar los ingresos medios a precios constantes en un 2,0\% entre 2008 y 2020 sólo consigue este resultado gracias a la aportación del sistema RGI/PCV/AES. Sin este apoyo, los ingresos de este grupo habrían caído un $-3,3 \%$.

Y, según he indicado en esta misma revista en una anterior ocasión (2018: 80-83), la desigualdad está muy relacionada con la falta de igualdad de oportunidades, aumentando el riesgo de pobreza, de exclusión y la adopción de decisiones desacertadas, generando depresión, síndrome de desgaste profesional, drogadicción, fracaso escolar, obesidad, infancias infelices, baja participación electoral y desconfianza social y política.

Y ¿cómo contribuiría la RBI que se propone a reducir la actual desigualdad en la CAPV? Una importante aproximación a la respuesta la ofrece el supuesto 2 b de Bollain (2021: 129-135), al ser un modelo de RBI, de cuantía igual al umbral de la pobreza de la CAPV para las personas mayores de edad y un $20 \%$ del mismo para las personas menores de 18 años, donde las pensiones y las prestaciones por debajo de la cuantía de la RBI no son consideradas como ahorro y, por lo tanto, no es absorbido. Además, incluye la introducción de una cláusula de compensación para que ningún hogar por debajo de la decila 8 reduzca sus ingresos. Pues bien, salen estos datos:

Con esta reforma conseguimos que, sin incluir los recursos destinados a la cláusula de compensación y a la eliminación de la pobreza, se realice una transferencia de 4.703.036.052€ del $20 \%$ de los hogares de las dos decilas con mayor renta al resto de la población. Asimismo, la redistribución total que finalmente se consigue, es de 4.982.076.703€. Una redistribución que equivale al 6,92\% del PIB de la CAPV en 2018.

En cuanto al número de personas ganadoras (de 18 o más ańos), podemos apreciar que en este supuesto son el 56,44\% del total de la población antes de establecer la cláusula de compensación. Una cláusula de compensación con la que se logra compensar al 3,69\% de las personas, elevando el porcentaje de las personas ganadoras y compensadas hasta el $60,13 \%$, frente al $39,87 \%$ de la población que ve su renta neta minorada en la situación ex post en comparación con la situación ex ante.

Antes de aplicar la cláusula de compensación el 49,61\% de las personas pensionistas son ganadoras. Por contra, el 50,39\% de las mismas ven reducidos su renta neta con la reforma fiscal propuesta. El 5,01\% de las personas pensionistas son compensadas mediante la cláusula de compensación, obteniendo como resultado final que, mientras el $45,39 \%$ de las personas pensionistas ven aminorada su renta neta en la situación expost, el 53,61\% de las mismas salen beneficiadas.

El coeficiente de Gini sobre la renta bruta se sitúa en el 0,3514 y tras la aplicación del IRPF ex ante, éste se reduce hasta el 0,3183. Con la reforma propuesta en 
este supuesto, sin embargo, logramos que el coeficiente de Gini se reduzca hasta el 0,1417. Sin duda, un valor que está muy lejos del 0,308 de la media de la Unión Europea de los 28 en el año 2018 e, incluso, de los países con mayor igualdad según dicho coeficiente. Como apuntábamos anteriormente, el país con un coeficiente de Gini más bajo en 2018 era Eslovaquia y éste se situó en el 0,209.

Es decir, en el supuesto $2 \mathrm{~B}$ logramos que, frente al efecto redistributivo del 0,0331 que tiene el actual sistema impositivo, éste incremente hasta el 0,2087, lo que implicaría reducir el índice de Gini en más de 20 puntos.

Por tanto, el nivel redistributivo de esta propuesta de RBI nos pondría en cabeza a la hora de luchar contra la desigualdad económica.

\section{Avanzar en otros grandes retos}

La RBI es un instrumento que, mejor que ningún otro, permite el avance en el cumplimiento de muchos derechos humanos y en los Objetivos de Desarrollo Sostenible 2030 de la ONU, en lo sucesivo ODS. Ya he hecho referencia a que permite materialmente poner fin a la pobreza (1. $\left.{ }^{\circ} \mathrm{ODS}\right)$, generar salud y bienestar (3..$^{\circ}$ ODS), repartir la riqueza y conseguir reducir las desigualdades (10. ${ }^{\circ}$ ODS). Pero igualmente, en la medida que genera condiciones materiales, permite acabar con el hambre ( $\left.2 .^{\circ} \mathrm{ODS}\right)$, posibilita disponer de tiempo y condiciones materiales para conseguir una educación de calidad (4. ${ }^{\circ}$ ODS), avanzar en la igualdad de género (5. ${ }^{\circ} \mathrm{ODS}$ ), acceder a energía asequible y no contaminante (7..$\left.^{\circ} \mathrm{ODS}\right)$, empoderar para obtener un trabajo decente y contribuir al crecimiento económico ( $8 .^{\circ}$ ODS), favorecer ciudades y comunidades sostenibles (11. $\left.{ }^{\circ} \mathrm{ODS}\right)$, alinearse con una producción y consumo responsables (12. ${ }^{\circ}$ ODS), sumarse a un estilo de vida respetuoso con el medio ambiente $\left(13 .^{\circ} \mathrm{ODS}\right)^{34}$, generar condiciones materiales que permitan la paz, la justicia y unas instituciones sólidas (16. ODS), así como tejer redes y alianzas para lograrlo (17. $\left.{ }^{\circ} \mathrm{ODS}\right)$.

Ya he desarrollado en otras ocasiones (2016: 6-11), (2017: 48-53), (2020: 238-239) que la RBI es una herramienta que presenta grandes virtualidades a la hora de abordar el mundo del trabajo, la reducción de la jornada, la educación

\footnotetext{
${ }^{34}$ La situación de emergencia climática ha sido declarada en el año 2019 por las distintas instituciones europeas, españolas y vascas, y ha sido precedida de distintas cumbres de Naciones Unidas, desde la de Estocolmo sobre la Tierra del siglo pasado, hasta las últimas sobre el Cambio Climático de París en el año 2015 y la de noviembre de 2021 en Glasgow. Sin embargo, la crisis ecológica no se soluciona solamente tratando de detener el cambio climático, sino que existen diversas dimensiones en el uso de los recursos finitos que también deben abordarse y esto requiere un cambio de rumbo en nuestro modelo económico, para lo que la RBI también es un instrumento útil, tal como se enuncia en el apartado III de la Exposición de Motivos de esta ILP.
} 
inclusiva, la igualdad de género, la democracia y la participación ciudadana, la juventud y la eficiencia de la administración, la creación de empresas con un modelo de economía social y solidaria. Quiero añadir que también está la pobreza encubierta experimentada por algunas personas, principalmente jóvenes, para acceder a una vida independiente como consecuencia de la falta de recursos económicos suficientes. La EPDS (Gobierno Vasco: 2021: 113) detecta 99.707 casos de personas que afirman desear constituir un nuevo hogar independiente, pero de ellas 77.583 seńalan no poder hacerlo por falta de ingresos adecuados ${ }^{35}$. Sin duda la RBI contribuiría a esa emancipación y, con ella, al desarrollo de un proyecto personal de vida digna.

Como conclusión de este artículo, considero que la RBI es instrumento de reparto de riqueza, que permite incrementar el grado de autonomía y libertad real de la ciudadanía, empoderándola en las elecciones laborales, de formación y de proyectos de vida, favoreciendo el emprendimiento de proyectos colaborativos y creando una sociedad más cohesionada. Pero en modo alguno es una panacea, por lo que debe complementar otras políticas públicas que se establezcan para mejorar el estado de bienestar. En todo caso, creo que es una buena oportunidad para que, en sintonía con el Prólogo del IV Plan Director de Cooperación para el Desarrollo 2018-2021 mencionado en la Introducción de este artículo, la mayoría de grupos presentes en el Parlamento Vasco apoye esta ILP.

\section{Bibliografía}

Asamblea Parlamentaria del Consejo de Europa (2018). Disponible en: http://assembly.coe.int/nw/xml/Votes/DB-VotesResults-EN.asp?VoteID=36977\&DocID=16 468\&MemberID = (accedido: 16-12-2021).

Asociación Red Renta Básica (2016). XVI Simposio de la Renta Básica. Bilbao. Disponible en: https:/www.ehu.eus/es/web/lan-harreman-gizarte-langintza-fakultatea/-/xvisimposio-renta-basica. (accedido: 16-12-2021).

Aust, Andreas y Arriba, Ana (2005). "Towards Activation? Social Assistance Reforms and Discourses», en Taylor-Gooby P. (ed.), Ideas and Welfare State Reform in Western Europe. Nueva York: Palgrave Macmillan. Disponible en: https://www.academia. edu/31883604/Policy_reforms_and_discourses_in_social_assistance_in_the_1990s_ Towards_activation (accedido: 16-12-2021).

Basic Income Earth Network. Disponible en: https://basicincome.org/about-basicincome/ (accedido: 16-12-2021).

35 Según esta Encuesta, de disponer de recursos suficientes 11.199 personas se emanciparían con total seguridad en un plazo máximo de un ańo, una cifra que aumenta a 30.282 personas si se incluye a las que se plantean tal posibilidad en ese plazo de un año. 47.300 personas sin ingresos suficientes se plantean, por su parte, un proceso de independización del actual hogar, aunque en un plazo superior a un año. 
Belaustegui Luis, Bollain Julen, Cerrato Javier, Elías Ángel y Peña Noemi (2016). "Clara mayoría social a favor de una RBI en la UPV/EHU». XVI Simposio sobre la Renta Básica. Bilbao. Disponible en https://www.ehu.eus/ documents/6902252/7260405/Comunicacion-Noemi-Pena-y-otros-Texto.pdf (accedido: 16-12-2021).

Bollain Urbieta, Julen (2021). Tesis doctoral: La viabilidad de una renta básica en la Comunidad Autónoma de Euskadi. Bilbao. UPV/EHU.

Clasen, Jochen (2001). "An offer you can't refuse»: workfare in international perspective, I. Lødemel and H. Trickey (eds). Bristol: Policy Press.

Comisión Promotora de una ILP para una RBI en la CAPV (2021). Disponible en: https://rentabasica.eus/es/quienes/ (accedido: 16-12-2021).

Comité de Asuntos Sociales, Salud y Desarrollo Sostenible de la Asamblea Parlamentaria del Consejo de Europa (2018). Disponible en: http://assembly.coe. $\mathrm{int} / \mathrm{nw} / \mathrm{xml} / \mathrm{XRef} / \mathrm{Xref}-\mathrm{XML} 2 \mathrm{HTML}-\mathrm{en}$.asp?fileid=24285\&lang=en (accedido: 1612-2021).

Comité DESC (1990). Observación General 3. Disponible en: https://tbinternet.ohchr. org/_layouts/15/treatybodyexternal/Download.aspx?symbolno=INT\%2FCESCR\%2 FGEC\%2F4758\&Lang=en (accedido: 16-12-2021).

Comité DESC (2018). Observaciones Finales al 6. ${ }^{\circ}$ Informe de España sobre el cumplimiento del PIDESC. Disponible en: https://tbinternet.ohchr.org/_layouts/15/treatybodyexternal/Download.aspx?symbolno=E/C.12/ESP/CO/6\&Lang=Sp (Accedido: 16-12-2021).

Consejo General del Trabajo Social de España (2020). Trabajo Social ante la garantía de rentas. Disponible en: http://www.cgtrabajosocial.es/app/webroot/files/consejo/ files/emergencias/Trabajo $\% 20$ social $\% 20$ Garanti\%C3\%ACa $\% 20 \mathrm{de} \% 20$ Rentas $\% 20$ 21.05.2020\%20(1).pdf (accedido: 16-12-2021).

Dhaliwal, Mandeep (2020). Bloc. Disponible en: https:/www1.undp.org/content/ undp/es/home/blog/2020/two-policies-we-need-to-recover-from-covid-19.html (Accedido: 16-12-2021).

Declaración Universal de Derechos Humanos Emergentes de Monterrey (2007). Disponible en: https://dhpedia.wikis.cc/wiki/Declaraci\%C3\%B3n_Universal_de_ Derechos_Humanos_Emergentes\#Texto_completo_de_la_Declaraci.C3.B3n (accedido: 16-12-2021).

De la Fuente, Mikel, Fernandez de Garaialde, Arantza y Longarte, Jose Luis (2019). "Una iniciativa social a recordar: la ILP por una Carta de Derechos Sociales», Naiz. Disponible en: https://www.naiz.eus/eu/iritzia/articulos/una-iniciativa-social-a-recordar-la-ilp-por-una-carta-de-derechos-sociales (accedido: 16-12-2021).

Elías, Angel y Rincón, Leire (2016). "Algunas virtualidades de la renta básica», Boletín Hegoa, 48. Disponible en: http://boletin.hegoa.ehu.es/mail/45 (accedido: 16-122021).

ELÍAs, Ángel y Rincón, Leire (2017). «Políticas que favorecen la inclusión», Zerbitzuan, 64, 48-50. Disponible en: http://www.zerbitzuan.net/documentos/zerbitzuan/Politicas_inclusion.pdf (accedido: 16-12-2021).

Elías Ortega, Ángel (2018). «Prestaciones sociales y reparto justo de la riqueza». Lan Harremanak - Revista de Relaciones Laborales. 40. 80-83. Disponible en https://doi. org/10.1387/lan-harremanak.20397 (accedido: 16-12-2021). 
ElíAs Ortega, Ángel (2020). «Oinarrizko errenta eta ekonomia social eta solidaria», Revista Vasca de Economía Social, 17, 225-244. Disponible en: https://ojs.ehu.eus/index. php/gezki/article/view/22234 (Accedido: 16-12-2021).

Fundación de Estudios Sociales y de Sociología Aplicada -Foessa- (2019). II Informe sobre exclusión y desarrollo social en el País Vasco. Disponible en: https:// www.caritasbi.org/cas/varios/informes/Informe_FoessaEuskadi_2019/Informe\%20 Foessa\%20Euskadi_cas.pdf (accedido: 16-12-2021).

Fundación de Estudios Sociales y de Sociología Aplicada -Foessa- (2021). Sociedad expulsada y derecho a ingresos, "Análisis y Perspectivas 2021» Disponible en: https:/www.caritas.es/main-files/uploads/2021/10/analisis-y-persectivas-2021.pdf (accedido: 16-12-2021).

Gobierno Vasco (2018) IV Plan Director de Cooperación para el Desarrollo. Disponible en: https://www.euskadi.eus/contenidos/plan_departamental/02_plandep_xileg/ es_def/adjuntos/IV\%20Plan\%20\%20Coop.\%20para\%20el\%20Desarrollo.pdf (accedido: 16-12-2021).

Gobierno Vasco (2021). Encuesta de Pobreza y Desigualdades Sociales 2020. Vitoria-Gasteiz: Departamento de Igualdad, Justicia y Políticas Sociales. Disponible en: https:// www.euskadi.eus/documentacion/2020/informe-epds-2020/web01-s2enple/es/ (accedido: 16-12-2021).

Hernanz, Virginia, Malherbet, Frank y Pellizzari, Michele (2004). «Take-Up of Welfare Benefi ts in OECD Countries: A Review of Evidence», Social, Employment, and Migration Working Paper 17. Paris: Organisation for Economic Co-operation and Development.

Iniciativa Legislativa Popular para una Renta Básica Incondicional en la Comunidad Autónoma del País Vasco (2021). Disponible en: https://rentabasica.eus/ wp-content/uploads/2021/02/prop_completa_es.pdf (accedido: 16-12-2021).

INVESTIGADORAS/ES Y PROFESORAS/ES DEL ÁMBITO ACADÉMICO, UNIVERSITARIO Y DE CENtros de investigación del País Vasco (2020). Manifiesto por una Economía Ecológica en la Euskal Herria Post Covid19. Disponible en: https://euskalherriapostcovid19. eus/es/inicio/ (accedido: 16-12-2021).

INVESTIGADORAS/ES Y PROFESORAS/ES DEL ÁMBITO ACADÉMICO, UNIVERSITARIO Y DE CENtros de investigación del País Vasco (2021). Libro Blanco de la Covid19. Disponible en: https://covid19liburuzuria.eus/es/ (accedido: 16-12-2021).

Ministerio de Inclusión, Seguridad Social y Migraciones (2021). El Ingreso Minimo Vital llega en mayo a 260.000 hogares en los que viven más de 680.000 personas. Disponible en: https://www.lamoncloa.gob.es/serviciosdeprensa/notasprensa/inclusion/Paginas/ 2021/170521-ingreso_minimo_vital.aspx (accedido: 16-12-2021).

Naciones Unidas (2021). Informe de los Objetivos de Desarrollo Sostenible. Disponible en: https://unstats.un.org/sdgs/report/2021/goal-03/ (accedido: 16-12-2021).

ORgANIZACIONES FEMINISTAS DE ESPAÑA (2020). Recursos y autonomía para todas: Un Manifiesto feminista a favor de la Renta Básica. Disponible en: https://news.un.org/es/ story/2020/07/1477601 (accedido: 16-12-2021).

Ortiz Isabel, Behrendt Christina, Acuña-Ulate Andrés y Nguyen Quynh Anh (2018). "Universal Basic Income proposals in light of ILO standards: Key issues and global costing", Organización Internacional del Trabajo. Extension of Social Security. Working Paper, 62, 26-30. Disponible en: https://www.ilo.org/wcmsp5/groups/ public/---ed_protect/---soc_sec/documents/publication/wcms_648602.pdf (accedido: 16-12-2021). 
Painter, Anthony (2017). «¿Es la renta básica universal la respuesta a la pobreza, la inseguridad y la desigualdad en materia de salud?», Viento Sur. Disponible en: https:// vientosur.info/es-la-renta-basica-universal-la-respuesta-a-la-pobreza-la-inseguridady-la/ (accedido: 16-12-2021).

Papa Francisco (2020). Soñemos Juntos. El camino a un futuro mejor. Madrid. Plaza Janés.

Papa Francisco (2021). Discurso en el IV Encuentro de Movimientos Populares. Disponible en: https://youtu.be/HmyroLCOHN4 —en el minuto 79 y siguientes del vídeo(accedido: 16-12-2021).

Profesionales del sector cultural en España (2020). Gente que trabaja en cultura, por una renta básica universal e incondicional. Disponible en: https://nativa.cat/2020/04/ gent-que-treballa-en-cultura-per-una-renda-basica-universal-i-incondicional/\#castella (accedido: 16-12-2021).

Profesionales sociales y educativos de España (2020). Manifiesto por una Renta Básica Universal. Disponible en: http://www.rendabasicaara.org/ (accedido: 16-122021).

Programa de las Naciones Unidas para el Desarrollo, PNUD (2020). Bloc. Disponible en: https://www1.undp.org/content/undp/es/home/blog/2020/two-policies-weneed-to-recover-from-covid-19.html (accedido: 16-12-2021).

Raventós, Daniel (2000). «El salario de toda la ciudadanía», Claves de razón práctica, 106.

Raventós, Daniel (2007). Las condiciones materiales de la libertad. Barcelona: El Viejo Topo.

Standing, Guy (2017). Basic Income: And How We Can Make It Happen. Londres: Penguin Books.

UPV/EHU (2021). Proyecto Estratégico Gaztebi. Disponible en: https://www.ehu.eus/es/ web/lan-harreman-gizarte-langintza-fakultatea/gaztebi (accedido: 16-12-2021).

VAn Parijs, Philippe (2006). «Basic Income: A simple and powerful idea for the 21 st century", en Wright E. O. (ed.), Redesigning Distribution. Basic Income and Stakeholder Grants as Cornerstones for an Egalitarian Capitalism. Londres: Verso.

Weiner, Bernard, Perry, Raymond P. y Magnusson, Jamie (1988). "An attributional analysis of reactions to stigmas", Journal of personality and social psychology, 55(5), 738.

Wignaraja, Kanni (2020). Disponible en: https://www1.undp.org/content/undp/es/ home/blog/2020/the-need-for-universal-basic-income.html (accedido: 16-12-2021).

Wignaraja, Kanni (2020). Disponible en: https://news.un.org/es/story/2020/07/1477601 (accedido: 16-12-2021).

World Inequality Lab (2021). Informe sobre la desigualdad mundial 2022. Disponible en https://wir2022.wid.world/ (accedido: 16-12-2021).

\section{Legislación}

Pacto Internacional de los Derechos Económicos, Sociales y Culturales (1966). BOE, n. ${ }^{\circ}$ 103, 30-4-1977. Disponible en https://www.ohchr.org/SP/ProfessionalInterest/ Pages/CESCR.aspx (accedido: 16-12-2021). 
Loi 88-1088, de 1 diciembre 1988, relative au revenu minimum d'insertion, Journal officiel de la République française, 3-12-1988. Disponible en https://www.legifrance.gouv. fr/loda/id/JORFTEXT000000875188/2021-10-31/ (accedido: 16-12-2021).

Ley 2/1990, de 3 de mayo, del Parlamento Vasco, de Ingreso Mínimo de Inserción. Disponible en https://www.boe.es/boe/dias/2012/02/29/pdfs/BOE-A-2012-2856.pdf (accedido: 16-12-2021).

Iniciativa Legislativa Popular por una Carta de Derechos Sociales «Aurkitu» (1997). Disponible en https://www.euskadi.eus/gobierno-vasco/-/asociacion/comision-promotora-de-una-iniciativa-legislativa-popular-por-una-carta-de-derechos-sociales-aurkitu/ (accedido: 16-12-2021).

Ley 12/1998, de 22 de mayo, del Parlamento Vasco, Contra la Exclusión Social. Disponible en https://www.boe.es/boe/dias/2011/12/31/pdfs/BOE-A-2011-20655.pdf (accedido: 16-12-2021).

Ley 10/2000, de 27 de diciembre, de Carta de Derechos Sociales, del Parlamento Vasco. BOPV n.o 249, 30-12-2000. Disponible en https://www.euskadi.eus/bopv2/ datos/2000/12/0005881a.pdf (accedido: 16-12-2021).

Ley 18/2008, de 23 de diciembre, del Parlamento Vasco, para la Garantía de Ingresos y para la Inclusión Social. BOPV n. ${ }^{\circ}$ 250, 31-12-2008. Disponible en https://www. euskadi.eus/bopv2/datos/2008/12/0807235a.pdf (accedido: 16-12-2021).

Ley 4/2011, de 24 de noviembre, del Parlamento Vasco, de modificación de la Ley para la Garantía de Ingresos y para la Inclusión Social. Disponible en https://www.lanbide. euskadi.eus/contenidos/informacion/rgi_normativa/es_def/adjuntos/1105924a.pdf (accedido: 16-12-2021).

Ley 10/2016, de 30 de junio, del Parlamento Vasco, reguladora de la Iniciativa Legislativa Popular. BOPV, n.o 129, 16-7-2016. Disponible en: https://www.legegunea.euskadi. eus/eli/es-pv/l/2016/06/30/10/dof/spa/html/webleg00-contfich/es/ (accedido: 16-122021).

Real Decreto Ley 20/2020, de 29 de mayo, por el que se establece el ingreso mínimo vital, BOE, n. ${ }^{\circ} 154,1-06-2020$. Disponible en: https://www.boe.es/eli/es/ rdl/2020/05/29/20/con (accedido: 16-12-2021). 